\title{
PROPOSTA DE METODOLOGIA PARA ZONEAMENTO AMBIENTAL DE PLANTIO DE EUCALIPTO
}

\author{
Márcio Rocha Francelinoํ, Estevão Machado Cidade de Rezende², Leonardo Duarte Batista da Silva ${ }^{3}$
}

(recebido: 9 de março de 2010; aceito: 22 de dezembro de 2011)

RESUMO: Conduziu-se este trabalho, com o objetivo de desenvolver uma metodologia de zoneamento ambiental para identificar áreas onde plantios de eucalipto possam ser desenvolvidos sem restrições ambientais e legais, utilizando o Município de Vassouras, no Estado do Rio de Janeiro, como estudo de caso. Foram considerados dados do meio físico, legislação ambiental, presença de áreas urbanas e o plano diretor municipal. Foram identificadas como zonas restritivas as áreas de preservação permanente, conforme a lei 4.771 de 1965 e suas alterações; as unidades de conservação e zonas de expansão industrial estabelecidas pelo plano diretor municipal; fragmentos florestais da mata atlântica e regiões próximas dos núcleos urbanos. Vassouras possui um território de 552 $\mathrm{km}^{2}$, destes, aproximadamente $144 \mathrm{~km}^{2}$ não apresentam nenhum tipo de restrição legal para o plantio de eucalipto, dos quais $97 \%$ estão atualmente ocupados por pastagens subutilizadas. Aproximadamente $93 \%$ das áreas sem restrições apresentam aptidão alta e média para a cultura do eucalipto.

Palavras-chave: Silvicultura, geoprocessamento, uso do solo.

\section{PROPOSAL OF A METHOD FOR ENVIRONMENTAL ZONING OF EUCALYPTUS PLANTATIONS}

\begin{abstract}
The objective of this work was to develop a method for environmental zoning of eucalyptus plantations, to identify areas where eucalyptus planting could be developed, and to determine suitability of such areas. The study area was the County of Vassouras, in the State of Rio de Janeiro, considering physical data, environmental legislation, urban areas, and the municipal land use plan. The areas for permanent preservation, as well as the conservation units and areas for industrial expansion, as defined in the county land use plan, plus areas nearby the city were considered restricted for the planting of eucalyptus trees. Vassouras is 552 $\mathrm{km}^{2}$ large. Approximately $144 \mathrm{~km}^{2}$ are suitable eucalyptus planting, of which 97\% are now used for pastures. Approximately 50\% of the area suitable for eucalyptus is of average suitability, whereas the class of highest suitability occupies about $30 \%$. The less suitable areas correspond to $20 \%$ of the remaining $144 \mathrm{~km}^{2}$.
\end{abstract}

Key words: Silviculture, geoprocessing, land use.

\section{INTRODUÇÃO}

O Brasil possui uma área total de 851 milhões de hectares, dos quais 450 milhões correspondem a florestas naturais (GUIMARÃES et al., 2006) e apenas 5,4 milhões de hectares $(0,6 \%$ do território nacional) estão ocupados com florestas plantadas, concentrados principalmente na região sudeste (ASSOCIAÇÃO BRASILEIRA DE PRODUTORES DE FLORESTAS PLANTADAS ABRAF, 2007). Segundo Amorim et al. (2009), a área reflorestada existente no Estado do Rio de Janeiro é de 18.427 ha, que corresponde a $0,42 \%$ da área total do estado, sendo que grande parte consiste em plantios de eucalipto (98\%).

No município de Vassouras, na região centro-sul fluminense, o cultivo do eucalipto foi introduzido em 1870, quando o médico Antônio Lazarini mandou plantar vários exemplares nas ruas da cidade e no jardim público. Como tal plantio coincidiu com o aparecimento da febre amarela na cidade, toda a população se revoltou e exterminou as árvores, julgando-as malignas e portadoras da doença (BERTOLA, 2011). Atualmente, essa atividade vem se desenvolvendo bem, em antigos pastos abandonados no município (AMORIM et al., 2012).

\footnotetext{
${ }^{1}$ Agrônomo, Professor Doutor em Solos e Nutrição de Plantas - Departamento de Silvicultura - Universidade Federal Rural do Rio de Janeiro/UFRRJ BR 465, km 07 - 23890-000 - Seropédica, RJ, Brasil - marciorocha@ufrrj.br

${ }^{2}$ Engenheiro Florestal - Centro de Sensoriamento Remoto/CSR - IBAMA - SCEN, trecho 2, ed. Sede - 70.818-900 - Brasília, DF, Brasil estevaozen@gmail.com

${ }^{3}$ Engenheiro Agrícola, Professor Doutor em Irrigação - Departamento de Engenharia - Universidade Federal Rural do Rio de Janeiro/UFRRJ - BR 465, km 07 - 23890-000 - Seropédica, RJ, Brasil - irriga@ufrrj.br
}

Cerne, Lavras, v. 18, n. 2, p. 275-283, abr./jun. 2012 
Segundo Empresa Brasileira de Pesquisa Agropecuária - Embrapa (2004), a produção de florestas plantadas não atende à demanda atual de madeira no Brasil, tendo como consequência a diminuição gradativa de áreas ocupadas por florestas naturais.

Segundo Sartori (2008), projeções indicam que em 2020 o Brasil terá cerca de 8 milhões de hectares de florestas plantadas. Para minimizar os impactos dessa expansão no meio ambiente, é necessário um planejamento que viabilize o uso racional dos recursos, proporcionando uma ocupação ordenada e melhor aproveitamento do espaço físico (MELLO FILHO, 1994), o que pode ser obtido por meio do zoneamento ambiental.

Segundo Rocha (1997), o zoneamento ambiental faz parte de um conjunto de ações ambientais desenvolvidas para orientar para o uso sustentável dos recursos naturais e consiste em dividir uma área em parcelas homogêneas, com características fisiográficas e ecológicas semelhantes, nas quais se recomendam determinados usos e atividades e se desaconselham outros. Para Schoenholtz et al. (2000), um zoneamento ambiental deve utilizar um modelo com formulações simples e guiadas pelo objetivo pretendido. Para Flores et al. (2011), as zonas de aptidão potencial podem ser determinadas a partir de um modelo que incorpore um vasto conjunto de dados, desenvolvido à escala regional, como ferramenta para a avaliação de cenários alternativos de ordenamento florestal.

Para a realização de um zoneamento direcionado a uma determinada atividade, primeiramente é necessário determinar os fatores que de alguma forma afetarão o sucesso ou não de tal empreendimento. Quando se trata de atividades silviculturais, os fatores ambientais são os principais elementos considerados, sendo a classe de solo, o relevo e o clima os fatores preponderantes para estabelecer as aptidões de cada unidade da paisagem (BOLDRINI, 2006). Braga et al. (1999) concluíram que as áreas de maior potencial produtivo na região do Médio Rio Doce foram as que apresentaram baixa declividade, exposição norte-nordeste, pedoforma côncava e posição mediana ou inferior na encosta, relativamente distantes dos topos da paisagem. Porém, outros fatores, além desses, tais como legislação, planos diretores e existência de unidades de conservação, podem também influenciar de maneira direta a expansão de determinadas culturas e, normalmente, não são considerados quando elaborados estudos ou propostas de zoneamento para culturas específicas.

No Estado do Rio de Janeiro, foi promulgada a Lei ${ }^{\circ} .5067$ de 09 de Julho de 2007, que dispõe sobre o zoneamento ecológico-econômico fluminense, definindo critérios para a implantação da atividade de silvicultura econômica no estado e reforça a necessidade de se estabelecer áreas qualificadas para esse tipo de atividade em observância às normas estabelecidas, visto o interesse crescente de produtores rurais de diversas regiões do estado no plantio de eucalipto.

Com o advento e avanço constante das ferramentas de geoprocessamento, é possível realizar zoneamentos ambientais de forma rápida e com resultados confiáveis (SILVA, 2001), pois permite a estruturação da base de dados espaciais e sua posterior sobreposição para a geração de novas informações de forma a alcançar os objetivos estabelecidos (RANIERI, 2007). Os sistemas de informações geográficas (SIGs) contornam as dificuldades logísticas que existem nos estudos em grandes escalas, possibilitando a manipulação integrada de conjuntos de diferentes dados (BURROUGH; MCDONNEL, 2005).

Neste trabalho, objetivou-se elaborar proposta de metodologia para realizar zoneamento ambiental para plantios de eucalipto considerando aspectos do meio físico e legais, por meio de um estudo de caso no Município de Vassouras, Estado do Rio de Janeiro.

\section{MATERIAL E MÉTODOS}

\section{1 Área de estudo}

O Município de Vassouras está localizado na região centro-sul fluminense (Figura 1), tendo uma população de aproximadamente 33.000 habitantes e uma área territorial com cerca de $552 \mathrm{~km}^{2}$ (INSTITUTO BRASILEIRO DE GEOGRAFIA E ESTATÍSTICA - IBGE, 2009). A região está inserida no domínio da Mata Atlântica e, como todo o Vale do médio Paraíba do Sul, era coberta por formações florestais que perduraram, sem significativas alterações, até o início do século XIX (GOLFARI; MOOSMAYER, 1980), tendo sido progressivamente substituídas por plantações de café e posteriormente por pastagens. As áreas abandonadas foram sendo ocupadas por florestas secundárias que atualmente se encontram em diferentes estágios sucessionais. A porcentagem de árvores caducifólias do estrato dominante é superior a $50 \%$, sendo seus gêneros mais importantes: Piptadenia (angico), Cariniana (jequitibá) e Cedrela (cedro) (RADAMBRASIL, 1983).

Segundo metodologia proposta por Köppen (1948), o clima da região foi classificado como Cwa, ou seja, mesotérmico úmido com temperatura média anual de $20^{\circ} \mathrm{C}$, com estação seca no inverno e precipitação média anual de $1.196 \mathrm{~mm}$.

Cerne, Lavras, v. 18, n. 2, p. 275-283, abr./jun. 2012 


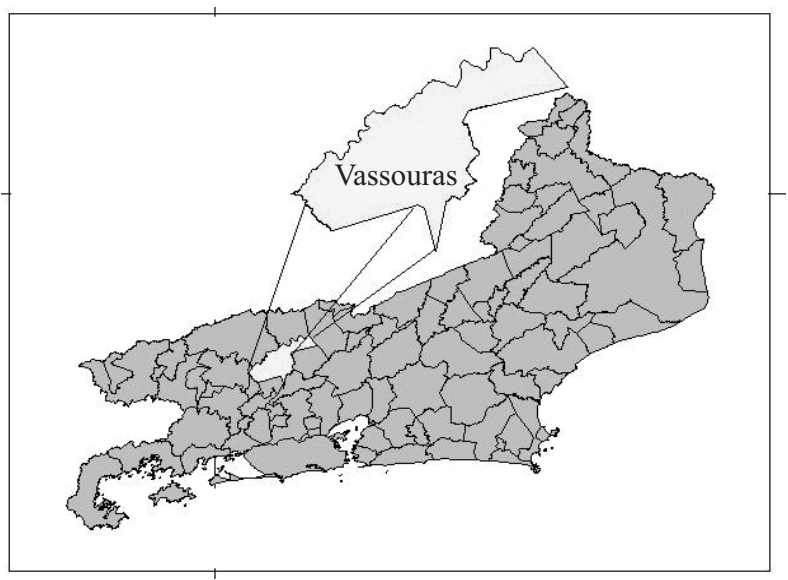

Figura 1 - Localização do Município de Vassouras no Estado do Rio de Janeiro.

Figure 1 - Location of the County of Vassouras in the State of Rio de Janeiro.

O balanço hídrico foi calculado pelo método de Thornthwaite e Mather (1955), com base em dados da estação meteorológicas de Vassouras, para o período de 1961 a 1990 (INSTITUTO NACIONAL DE METEOROLOGIA - INMET, 2010), considerando valores de CAD (capacidade de água disponível) correspondente a cada unidade de mapeamento de solo do Município de Vassouras (inclusive foram consideradas as associações), conforme descrito pela Fundação Estadual de Proteção Ambiental do Rio Grande do Sul - FEPAM (2008) (Tabela 1). Para tanto, utilizou-se a planilha eletrônica desenvolvida por Sentelhas et al. (1998).

Tabela 1 - Capacidade de água disponível para espécies florestais exóticas para diferentes classes de solos.

Table 1 - Capacity of available water for exotic forest species for different soil classes.

\begin{tabular}{lc}
\hline Solos & CAD $(\mathrm{mm})$ \\
\hline Latossolo Vermelho-Amarelo distrófico & 350 \\
Argissolo Vermelho-Amarelo distrófico & 350 \\
Argissolo Vermelho-Escuro eutrófico & 300 \\
Argissolo Vermelho-Amarelo eutrófico & 225 \\
Cambissolo Háplico eutrófico & 200 \\
\hline
\end{tabular}

Fonte: FEPAM (2008)

\subsection{Levantamento dos dados}

Para gerar o mapa de uso do solo, foi utilizado mosaico de imagens orbitais do sistema Quick Bird com resolução espacial de 0,6 metros, obtidas em julho de 2008, cobrindo todo o território do município. O mapa foi gerado utilizando o programa Arcview 9.3, no formato shapefile, na escala de 1:10.000, sendo consideradas as seguintes classes: Mata (Floresta secundária em estágio sucessional médio e avançado), Capoeira (Floresta em estágio de sucessão inicial), Pastagem, Solos expostos, Áreas urbanas, Agricultura e Reflorestamento.

Foram utilizadas bases cartográficas do IBGE vetorizadas na escala 1:50.000, das seguintes cartas: Vassouras, Barra do Piraí, Paraíba do Sul, Valença, Paracambi e Miguel Pereira, sendo processados os dados de curvas de níveis e drenagem, que foi ajustada a partir da imagem orbital.

As informações de solos foram obtidas do mapa de solos do Rio de Janeiro, na escala 1:250.000, produzido por Carvalho Filho et al. (2000), o qual foi vetorizado utilizando também o programa Arcview 9.3. O modelo digital de elevação do terreno (MDE) foi obtido a partir interpolação das curvas de níveis do IBGE.

As áreas de preservação permanente (APP) foram geradas de acordo com a lei 4.771, de 1965 e Resolução 303, de 20/03/2002 do CONAMA (Conselho Nacional do Meio Ambiente). Todas as APPs foram geradas utilizando ferramentas do programa ArcGis 9.3. As APPs de nascentes e margens de rios e lagos foram geradas utilizando o comando buffer. As áreas com declividade igual ou superior a $45^{\circ}$ foram delimitadas a partir do mapa de declividade, obtido do MDE, utilizando o comando slope e, posteriormente, reclassificadas para a classe de interesse. As APPs de topo de morro foram obtidas a partir do modelo digital de elevação, considerando os conjuntos dos morros cujos topos estivessem com distância entre si iguais ou menores a 500 metros, conforme metodologia desenvolvida por Peluzio et al. (2010). Para cada conjunto determinado, o MDE foi reclassificado para a altitude referente ao terço médio superior.

\subsection{Determinação das áreas disponíveis para plantios de eucalipto}

Primeiramente, determinaram-se todas as áreas inaptas ao plantio de eucalipto, considerando os seguintes fatores:

- Faixa de 0,6 quilômetros das áreas urbanas, compostas pela sede municipal e núcleos distritais, conforme determinação da Lei N N $^{\circ} 5.067$ de 09 de Julho de 2007.

- Áreas ocupadas por remanescentes de vegetação nativa nos estágios primário e secundário inicial, médio

Cerne, Lavras, v. 18, n. 2, p. 275-283, abr./jun. 2012 
e avançado de regeneração, conforme levantado no mapa de uso do solo, seguindo recomendações da Lei 11.428 de 22/12/2006.

- Áreas destinadas à preservação e/ou conservação, bem como as zonas industriais, conforme indicado no Plano Diretor municipal (VASSOURAS, 2007).

- As áreas de preservação permanente conforme Lei 4.771 de 1965 (Código Florestal) e suas alterações (Resoluções CONAMA 3023 303).

As áreas restantes foram consideradas como aptas para receber plantios de eucalipto, as quais, posteriormente, foram classificadas em relação ao nível de aptidão: alto, médio e baixo. Para isso, foram considerados os temas de declividade, face de exposição e aptidão agrícola das terras, de forma a avaliar a influência de cada fator desse no desenvolvimento do eucalipto.

\subsubsection{Declividade}

Foram considerados valores de pesos para cada classe de declividade, conforme influência nas atividades silviculturais (Tabela 2), onde maiores declividades implicam maiores dificuldades na instalação do povoamento, tratos culturais, colheita e transporte, conforme descrito em Caldas (2006). Valores maiores indicam classes mais favoráveis e vice-versa.

Tabela 2 - Classes de declividade e pesos em relação à aptidão para plantio de eucalipto.

Table 2-Slope classes and weight value for eucalyptus plantation.

\begin{tabular}{ccc}
\hline Graus de declividade $(\%)$ & Classe & Peso \\
\hline 0 a 3 & Plano & 3 \\
3 a 8 & Suave ondulado & 3 \\
8 a 20 & Ondulado & 2 \\
20 a 45 & Forte ondulado & 2 \\
45 a 75 & Montanhoso & 1 \\
Maior que 75 & Escarpado & 0 \\
\hline
\end{tabular}

\subsubsection{Orientação das encostas}

A modelagem da radiação solar tem sido utilizada como um dos fatores que influencia a produtividade de áreas florestadas em grande escala (KUMAR; SKIDMORE, 2000). Stapea et al. (2004), estudando fatores ambientais que afetam a produtividade de plantações de eucalipto em São Paulo, verificaram que, além da água e $\mathrm{N}$, a quantidade de radiação solar também influenciou na produtividades dos talhões. Braga et al. (1999) concluíram que a radiação solar foi uma das características ambientais mais importante na produtividade de eucalipto cultivados no Médio Rio Doce (MG).

$\mathrm{Na}$ latitude da área de estudo, as encostas voltadas para sul recebem a luz solar direta pela parte da manhã, enquanto que as faces voltadas para norte e noroeste, recebem predominantemente na parte da tarde, o que lhes conferem um ambiente mais seco. Correa (2008), estudando os efeitos da direção das encostas em municípios nos Estados do Rio de Janeiro e Minas Gerais conclui que as faces voltadas para sul e sudeste apresentaram um número maior de áreas que apresentavam regeneração natural e relacionou isso a variações decorrentes de estarem mais ou menos expostas às radiações solares. Reuter et al. (2005) observaram um padrão distinto entre as faces sul e norte, os quais influenciaram no tipo de uso do solo e na distribuição de umidade no solo e, consequentemente, no desenvolvimento de culturas agrícolas.

O tema face de exposição foi gerado a partir do modelo digital de elevação, usando o comando aspect do Arcview 9.3. A seguir as orientações foram reclassificadas e separadas em 4 classes: norte, sul, leste e oeste, sendo adicionados pesos maiores (valor 3 ) para as áreas expostas com sentido sul e pesos menores (valor 1) para as faces voltadas para o norte. As faces voltadas para leste e o oeste receberam valores intermediários, 2,25 e 1,75 respectivamente.

Essa indicação não é impeditiva, apenas demonstra quais áreas possuem atributos que podem favorecer o desenvolvimento e a produtividade do eucalipto.

\subsubsection{Aptidão agrícola}

Foram adicionados pesos considerando o nível de Aptidão Agrícola das Terras, levando em conta os grupos de aptidão encontrados para o município de Vassouras, conforme Carvalho Filho et al. (2000):

- Grupo 3 (Terras indicadas para lavouras): peso 3;

- Grupo 4 (Terras indicadas para pastagem plantada): peso 2; e

- Grupo 6 (Terras indicadas para preservação da flora e da fauna): peso 0 .

\subsection{Mapa de aptidão para o cultivo do eucalipto}

O mapa de aptidão foi gerado a partir da combinação dos pesos atribuídos a declividade, face de exposição e solos, por meio de álgebra de mapas. O resultado final foi um novo mapa matricial cujos valores das células variaram de 3 a 9 , sendo que os valores mais altos representavam as áreas mais aptas ao desenvolvimento das atividades

Cerne, Lavras, v. 18, n. 2, p. 275-283, abr./jun. 2012 
silviculturais. Posteriormente, esse mapa foi reclassificado de forma a gerar somente três feições conforme o grau de aptidão: alto, correspondendo aos valores 9 a 7; médio, considerando os valores entre 6,99 e 5 e baixo, valores abaixo de 5. Para a separação das classes, foi utilizada a ferramenta Natural Breaks do programa ArcGis 9.3.

\section{RESULTADOS E DISCUSSÃO}

Apesar de ter sido um dos primeiros lugares a cultivar o eucalipto no Brasil, as atividades silviculturais ainda são bastante incipientes no Município de Vassouras. Segundo IBGE (2009), a produção em 2009 foi de apenas $397 \mathrm{~m}^{3}$, destinada principalmente para lenha e serraria. Esta situação é confirmada pelo mapeamento de uso do solo, onde a classe de reflorestamento ocupou apenas 70 ha, representando $0,1 \%$ do território do município (Tabela 3).

Tabela 3 - Áreas ocupadas pelas classes de uso e ocupação do solo.

\section{Table 3 - Land use distribution.}

\begin{tabular}{lcc}
\hline Classe & Área (ha) & Área (\%) \\
\hline Pastagem & 33.290 & 60,2 \\
Capoeira & 10.856 & 19,6 \\
Mata & 8.694 & 15,7 \\
Urbano & 1.073 & 1,9 \\
Agricultura & 601 & 1,1 \\
Água & 404 & 0,7 \\
Solo exposto & 187 & 0,3 \\
Várzea & 86 & 0,2 \\
Reflorestamento & 70 & 0,1 \\
\hline
\end{tabular}

A pecuária de corte é uma das principais atividades econômicas da região, onde as pastagens ocupam aproximadamente $60 \%$ da área do município, o que representa 33.290 ha. Porém, segundo IBGE (2010), o rebanho bovino efetivo é de 35.709 cabeças, o que resulta na ocupação aproximada de $1 \mathrm{UA} / \mathrm{ha}$, muito inferior à capacidade de suporte descrito por Euclides (2000) de 15 UA/ha no verão e $4 \mathrm{UA} /$ ha no inverno. Matas e capoeiras somam aproximadamente $35 \%$ do território municipal, indicando resguardo considerável de remanescentes da Mata Atlântica.

As áreas de preservação permanente (APPs) somam 20.803 ha, sendo que as de topo de morro ocupam aproximadamente metade dessas áreas (Tabela 4), em decorrência do relevo acidentado da região.

Tabela 4 - Áreas ocupadas pelas APPs.

Table 4 - Areas occupied by APP's.

\begin{tabular}{lcc}
\hline \multirow{2}{*}{ APP } & \multicolumn{2}{c}{ Área } \\
\cline { 2 - 3 } & ha & $\%$ \\
\hline Topos de morros & 9.826 & 47,2 \\
Margem de rios & 8.097 & 38,9 \\
Rio Paraíba do Sul & 1.353 & 6,5 \\
Nascentes & 1.076 & 5,2 \\
Encosta & 451 & 2,2 \\
\hline Total & 20.803 & 100 \\
\hline
\end{tabular}

Em relação ao balanço hídrico, pode-se verificar na Tabela 5 que para os diferentes solos presente no município, tem-se o valor de déficit hídrico anual acumulado, obtido por meio do balanço hídrico de Thornthwaite e Mather (1955), variando entre 15,2 e 42,4 mm, conforme o solo; sendo assim, esses valores são inferiores aos mencionados por Carneiro et al. (2006) e Napo et al. (2005) de 120 mm.ano ${ }^{-1}$ e $400 \mathrm{~mm}^{-a_{n}{ }^{-1}}$, respectivamente, como limite máximo para as diferentes espécies de eucalipto. Esses valores de déficits indicam que não há restrição hídrica para o desenvolvimento da cultura do eucalipto no Município de Vassouras, independentemente da classe de solo analisada.

Tabela 5 - Balanço hídrico $(\mathrm{mm})$ para os solos do Município de Vassouras.

Table 5 - Water balance ( $\mathrm{mm}$ ) for soil in the Vassouras county.

\begin{tabular}{ccc}
\hline CAD* $^{*}$ & Deficiência & Excesso \\
\hline 350 & 15,2 & 319,7 \\
300 & 17,5 & 321,8 \\
225 & 22,5 & 326.8 \\
200 & 24,8 & 339,2 \\
100 & 42,4 & 346,7 \\
\hline
\end{tabular}

* Capacidade de água disponível

\section{1 Áreas disponíveis para cultivo de plantios de eucalipto}

Conforme a metodologia aplicada, 14.465 ha do Município de Vassouras não apresentam restrições legais ao desenvolvimento de plantios de eucalipto, correspondendo a $26 \%$ do município (Figura 2).

Cerne, Lavras, v. 18, n. 2, p. 275-283, abr./jun. 2012 


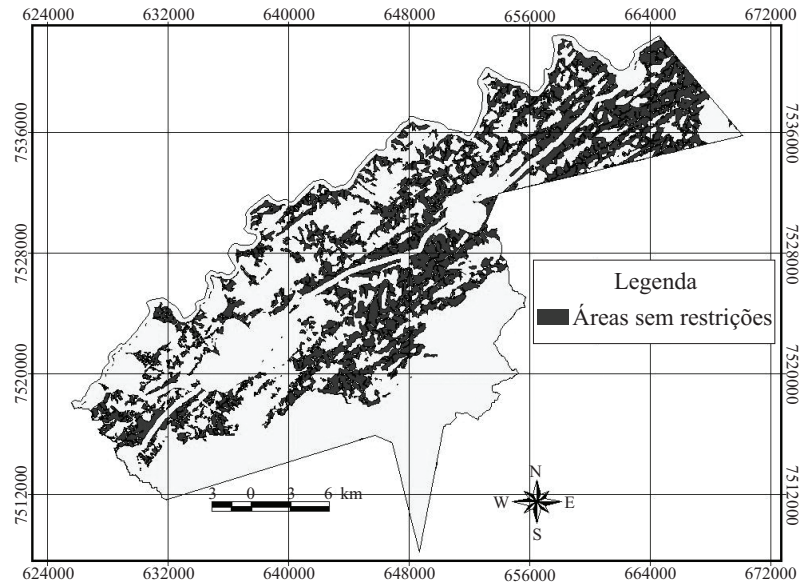

Figura 2 - Áreas sem restrições para cultivo de eucalipto em Vassouras, RJ.

Figure 2 - Areas restriction-free for cultivation of eucalyptus in Vassouras, RJ.

As áreas destinadas a unidades de conservação no município são os parques Catarina, Serra Grande e o corredor Bocaina-Tinguá, além da zona industrial, que margeia a BR-393, que juntas somam 14.927 ha (Tabela 6). A faixa de 600 metros em torno das áreas urbanas totalizou quase 6 mil ha. Observa-se, na Tabela 6, que a soma das áreas ultrapassam a área total do município (55.244 ha). Isso ocorre em razão da sobreposição de algumas áreas, principalmente as ocupadas com vegetação nativa, que podem estar ocorrendo tanto dentro das APPs como nas unidades de conservação, ou mesmo no entorno das áreas urbanas.

Tabela 6 - Áreas com restrições ao cultivo de eucalipto em Vassouras-RJ.

Table 6 - Areas with restrictions on cultivation of eucalyptus in the County of Vassouras.

\begin{tabular}{lc}
\hline Descrição & Área (ha) \\
\hline Zonas de uso restrito conforme Plano Diretor & 14.927 \\
Áreas ocupadas com vegetação nativa & 19.551 \\
Áreas de preservação permanente & 20.803 \\
Faixa de 0,6 km em torno das áreas urbanas & 5.840 \\
Disponível para plantio & 14.465 \\
\hline
\end{tabular}

A maior parte (97\%) das áreas disponíveis para o cultivo está ocupada por pastagens (Tabela 7), que, na maioria das vezes, encontram-se degradadas, conforme verificado nas imagens analisadas e confirmadas em viagem de campo e subutilizadas. $O$ estado precário das pastagens pode ocasionar sérios impactos ambientais, em razão, principalmente das perdas de solos (ENDRES et al., 2006), principalmente em regiões com relevo movimentado, como é o caso em estudo. Caso o desenvolvimento da silvicultura na região esteja associado à exigência de adequação ambiental das propriedades, poderá ser um importante instrumento de melhorias, tanto dos recursos naturais como na renda dos proprietários rurais.

Tabela 7 - Tipologia de uso do solo nas áreas onde o cultivo de eucalipto pode ser desenvolvido.

Table 7 - Land use in areas where eucalyptus plantation can be located.

\begin{tabular}{lcc}
\hline Classe & Área (ha) & Área (\%) \\
\hline Pastagem & $14.028,1$ & 96,9 \\
Agricultura & 318,1 & 2,2 \\
Solo Exposto & 83,0 & 0,5 \\
Reflorestamento & 35,5 & 0,2 \\
\hline Total & $14.464,9$ & 100 \\
\hline
\end{tabular}

Vale ressaltar que neste estudo não foram consideradas as reservas legais em razão da falta de dados disponíveis, o que ocasionará a diminuição ainda mais da área sem restrição.

\subsection{Classes de aptidão para o desenvolvimento da silvicultura}

Cerca de $80 \%$ do Município de Vassouras encontrase entre as classes de relevo forte ondulado e montanhoso com orientação preferencial de suas vertentes na direção norte $(30 \%)$, contra $22 \%$ voltadas para o sul, $23 \%$ e $26 \%$ para o leste e oeste respectivamente. Os Argissolos Vermelho-Amarelos são os solos dominantes no Município de Vassouras, constituindo tanto os de natureza distrófica como eutrófica.

O município apresentou cerca de $80 \%$ das suas terras classificadas em algum dos subtipos do grupo de aptidão agrícola 3, porém todos com restrições para agricultura em algum dos níveis de manejo (Tabela 8). Isso ocorreu principalmente devido ao relevo acidentado da região. As áreas que apresentaram aptidão no grupo 6 estão concentradas em uma das áreas destinadas a conservação (Corredor Bocaina-Tinguá), localizada ao sul de Vassouras.

Cerne, Lavras, v. 18, n. 2, p. 275-283, abr./jun. 2012 
Tabela 8 - Grupos de aptidão agrícola das terras.

Table 8 - Land suitability group.

\begin{tabular}{|c|c|c|}
\hline Aptidão & Descrição & Área (ha) \\
\hline $3(\mathrm{bc})^{*}$ & Aptidão restrita para culturas especiais de ciclo longo nos níveis de manejo $\mathrm{B}$ e $\mathrm{C}$ e inapta no nível A & $9.291,0$ \\
\hline $3(\mathrm{ab})$ & Aptidão restrita para lavouras nos níveis de manejo A e B e inapta no nível C & $10.388,9$ \\
\hline $3(\mathrm{abc})^{*}$ & $\begin{array}{l}\text { Aptidão restrita para lavouras nos níveis de manejo A e para cultura especiais de ciclo longo nos } \\
\text { níveis de manejo B e C }\end{array}$ & $11.856,7$ \\
\hline $3(\mathrm{abc})$ & Aptidão restrita para lavouras nos níveis de manejo A, B e C & $5.196,0$ \\
\hline $3(\mathrm{bc})$ & Aptidão restrita para lavouras nos níveis de manejo $\mathrm{B}$ e $\mathrm{C}$ e inapta no nível $\mathrm{A}$ & $6.889,2$ \\
\hline $4(p)$ & Aptidão restrita para pastagem plantada & $10.784,7$ \\
\hline 6 & Sem aptidão para uso agrícola, terras indicadas para preservação de flora e fauna & 854,5 \\
\hline
\end{tabular}

Fonte: Carvalho Filho et al. (2000)

Verificou-se a existência de padrões distintos na distribuição das classes de aptidão para o desenvolvimento da silvicultura em Vassouras (Figura 3). Na região próxima das margens do Rio Paraíba do Sul, ocorreu uma concentração de zonas de baixa aptidão, enquanto que as melhores áreas estão localizadas no centro e nordeste do município, próximo da BR-393, o que facilitaria o escoamento da produção.

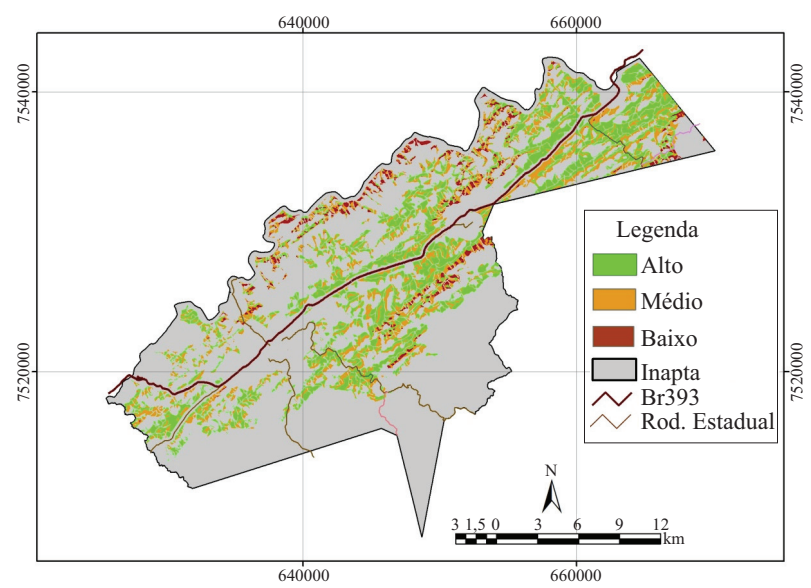

Figura 3 - Mapa de aptidão para plantio de eucalipto no Município de Vassouras, RJ.

Figure 3-Map of land suitability for eucalyptus plantations in the County of Vassouras- RJ.

As classes de aptidões alta e média foram predominantes no município, representando quase 93\% de toda a área disponível para plantio de eucalipto, o que indica um grande potencial dessa região para esse tipo de atividade (Tabela 9). Isso ocorreu em razão das condições ambientais favoráveis ao desenvolvimento dessa cultura, o que pode se constituir como mais uma alternativa econômica para Vassouras.

Tabela 9 - Classes de aptidão para silvicultura.

Table 9 -Silviculture suitability classes.

\begin{tabular}{lcc}
\hline \multirow{2}{*}{ Classes } & \multicolumn{2}{c}{ Área } \\
\cline { 2 - 3 } & ha & $\%$ \\
\hline Baixo & 1027 & 7,1 \\
Médio & 5920 & 40,9 \\
Alto & 7518 & 52,0 \\
\hline
\end{tabular}

\section{CONCLUSÕES}

A metodologia apresentou-se simples e aplicável, embora seja dependente de ferramentas de geoprocessamento, podendo ser adaptada às especificidades de diferentes regiões. A determinação prévia das áreas aptas a receber o cultivo do eucalipto permite uma redução de custo e tempo quando comparado com os métodos tradicionais de zoneamento, visto reduzir a área a ser avaliada em nível de aptidão. Considerando o estudo de caso, o Município de Vassouras possui 14.470 ha sem restrições legais para o desenvolvimento de atividades silviculturais, representando $26 \%$ da área do município. Destes, $97 \%$ estão atualmente ocupados por pastagens subutilizadas e aproximadamente $93 \%$ apresentam aptidão alta e média ao desenvolvimento da cultura.

\section{AGRADECIMENTOS}

Os autores agradecem à Prefeitura Municipal de Vassouras por disponibilizar as imagens utilizadas.

Cerne, Lavras, v. 18, n. 2, p. 275-283, abr./jun. 2012 


\section{REFERÊNCIAS}

AMORIM, H. B.; FRANCELINO, M. R.; MOURA, T. A.; CAPITANO, R. Estimativa da área ocupada por reflorestamentos no Estado do Rio de Janeiro. Cerne, Lavras, v. 18, n. 1, p. $27-$ $32,2012$.

\section{ASSOCIAÇÃO BRASILEIRA DE PRODUTORES DE FLORESTAS PLANTADAS. Anuário estatístico da}

ABRAF: ano base 2006. Brasília, 2007. 342 p.

BERTOLA, A. Eucalipto: 100 anos de Brasil. Disponível em: $<$ http://pt.scribd.com/doc/44587685/Eucalipto-100-Anos-deBrasil $>$. Acesso em: 10 maio 2011.

BOLDRINI, I. I. Biodiversidade dos campos do planalto das araucárias. In: Relatório final do Ministério do Meio Ambiente. Brasília: MMA/SBF, 2006. p. 101-116.

BRAGA, F. A.; BARROS, N. F.; SOUZA, A. L.; COSTA, L. M. Características ambientais determinantes da capacidade produtiva de sítios cultivados com eucalipto. Revista Brasileira de Ciência do Solo, Campinas, v. 23, p. 291-298, 1999.

BURROUGH, P. A.; MCDONNEL, R. A principle of geographical information systems. Oxford: Oxford University, 2005. 333 p.

CALDAS, A. J. F. S. Geoprocessamento e análise ambiental para a determinação de corredores de habitat na Serra da Concórdia, Vale do Paraíba, RJ. 2006. 178 p. Dissertação (Mestrado em Ciências Ambientais e Florestais) - Universidade Federal Rural do Rio de Janeiro, Seropédica, 2006.

CARNEIRO, M. A.; DANIEL, O.; VITORINO, A. T.; COMUNELLO, E. Aptidão da bacia do rio Dourados para o cultivo de algumas espécies de eucaliptos. Floresta, Curitiba, v. 36, n. 3, p. 331-342, 2006.

CARVALHO FILHO, A.; LUMBRERAS, J. F.; LEMOS, A. L.; SANTOS, R. D.; CALDERANO FILHO, B.; WITTERN, K. P.; SOUZA, F. S. Os solos do Estado do Rio de Janeiro. Brasília: CPRM, 2000. 1 CD-ROM.

CORREA, M. P. Influência da radiação solar na regeneração natural de mata Atlântica. 2008. 48 p.

Cerne, Lavras, v. 18, n. 2, p. 275-283, abr./jun. 2012
Monografia (Graduação em Engenharia Florestal) Universidade Federal Rural do Rio de Janeiro, Seropédica, 2008.

\section{EMPRESA BRASILEIRA DE PESQUISA}

AGROPECUÁRIA. Florestas: a Embrapa conserva este patrimônio. Brasília: Ministério da Agricultura, Pecuária e Abastecimento, 2004. 26 p.

ENDRES, P. F.; PISSARRA, T. C. T.; BORGES, M. J.; POLITANA, W. Quantificação das classes de erosão por tipo de uso do solo no município de Franca, SP. Revista de Engenharia Agrícola, Jaboticabal, v. 26, n. 1, p. 200-207, jan./abr. 2006.

EUCLIDES, V. P. B. Alternativas para intensificação da produção de carne bovina em pastagem. Campo Grande: Embrapa Gado de Corte, 2000. 65 p.

FLORES, C. A.; ALBA, J. M. F.; GARRASTAZÚ, M. C. Zoneamento edáfico para o eucalipto na região do Corede Sul. Disponível em: $<$ http://www.infobibos.com/ Artigos/2009_2/eucalipto/index.htm $>$. Acesso em: 29 maio 2011.

FUNDAÇÃO ESTADUAL DE PROTEÇÃO AMBIENTAL DO RIO GRANDE DO SUL. Base dos estudos de fauna, flora e recursos hídrico. Porto Alegre, 2008. v. 3, 101 p. Disponível em: $<$ http://www.fepam.rs.gov.br/biblioteca/ zoneam_silvic.asp>. Acesso em: 10 maio 2011.

GOLFARI, L.; MOOSMAYER, H. Manual de reflorestamento do Estado do Rio de Janeiro. Rio de Janeiro: Governo do Estado do Rio de Janeiro, 1980. 129 p.

GUIMARÃES, R. F.; CARVALHO JÚNIOR, O. A. de; MARTINS, E. S.; GOMES, R. A. T.; FLOSS, P. A.; ESPÍRITO SANTO, F. R. C. do; ANDRADE, A. C. de; CARVALHO, A. P. F. Definição de áreas para silvicultura na bacia do rio ariranha (SC) em áreas de encosta erosionais utilizando imagens ASTER e modelo digital de terreno. In: SIMPÓSIO BRASILEIRO DE SENSORIAMENTO REMOTO, 12., 2006, Goiânia. Anais... Goiânia: INPE, 2006. p. $1563-1566$.

INSTITUTO BRASILEIRO DE GEOGRAFIA E ESTATÍSTICA. Cidades. Disponível em: $<$ http://www.ibge. gov.br/cidadesat>. Acesso em: 27 ago. 2009. 
INSTITUTO NACIONAL DE METEOROLOGIA. Balanço hídrico climático da estação de Vassouras, RJ. Disponível em: <http://www.inmet.gov.br/html/agro. php?lnk $=\mathrm{H} \%$ EDdrico $\% 20 \mathrm{Clim} \%$ E1 tico $>$. Acesso em: 5 maio 2011.

KÖPPEN, W. Climatologia: con un estudio de los climas de la Tierra. Ciudad del Mexico: Fondo de Cultura Econômica, 1948. $479 \mathrm{p}$.

KUMAR, L.; SKIDMORE, A. K. Radiation-vegetation relationships in a eucalyptus forest. Photogrammetric Engineering \& Remote Sensing, Falls Church, v. 66, n. 2, p. 193-204, 2000.

MELLO FILHO, J. A. Estudo de microbacias hidrográficas, delimitadas por compartimento geomorfológicos, para o diagnóstico Físico Conservacionista. 1994. 111 f. Dissertação (Mestrado em Engenharia Florestal) Universidade Federal de Santa Maria, Santa Maria, 1994.

PELUZIO, T. M. O.; SANTOS, A. R.; FIEDLER, N. C. Mapeamento de áreas de preservação permanente no Arcgis 9.3. Alegre: CSUFES, 2010. 58 p.

RADAMBRASIL. Mapas geológico, geomorfológico, de vegetação, de avaliação do relevo, de capacidade de uso dos recursos naturais renováveis, exploratório de solos, levantamento de recursos naturais. Rio de Janeiro: MME, 1983. Folhas SF 23/24.

RANIERI, V. E. L. Zoneamento ambiental do município de Brotas (SP): subsídios ao planejamento territorial. São Paulo: CENTROVIAS/FIPA/USP, 2007. 39 p.

REUTER, H. I.; KERSEBAUM, K. C.; WENDROTH, O. Modeling of solar radiation influenced by topographic shading: evaluation and application for precision farming. Physics and Chemistry of the Earth, Oxford, v. 30, p. 143-149, 2005.

ROCHA, J. S. M. da. Manual de projetos ambientais. Brasília: MMA, 1997. 446 p.

SARTORI, P. A. Estudo sobre a evolução da área plantada de eucalipto e pinus no Brasil. Revista Científica Eletrônica de Engenharia Florestal, Garça, n. 11, p. 139-145, 2008.

SCHOENHOLTZ, S. H.; MIEGROET, H. van; BURGER, J. A. A review of chemical and physical properties as indicators of forest soil quality: challenges and opportunities. Forest Ecology and Management, Amsterdam, v. 138, p. 335-356, 2000.

SENTELHAS, P. C. et al. BHBRASIL: balanços hídricos climatológicos de 500 localidades brasileiras. Piracicaba: ESALQ, 1998. Disponível em: <http://www.lce.esalq.usp.br/ nurma.html $>$. Acesso em: 5 maio 2011.

SILVA, J. X. Geoprocessamento para análise ambiental. Rio de Janeiro: [s.n.], 2001. 227 p.

STAPEA, J. L.; BINKLEYB, D.; RYAN, M. G. Eucalyptus production and the supply, use and efficiency of use of water, light and nitrogen across a geographic gradient in Brazil. Forest Ecology and Management, Amsterdam, v. 193, p. 17-31, 2004.

THORNTHWAITE, C. W.; MATHER, J. C. The water balance. Centeron: Drexel Institute of Technology, 1955. 104 p.

VASSOURAS. Prefeitura Municipal. Plano diretor municipal. Vassouras: Secretaria Municipal de Planejamento, 2007. $263 \mathrm{p}$.

Cerne, Lavras, v. 18, n. 2, p. 275-283, abr./jun. 2012 